\title{
Gesture based Home Automation using Sixth Sense Technology
}

\author{
Shreya Apte \\ Department of Computer \\ Engineering, Sinhgad Institute of \\ Technology and Science, Pune- \\ 411041, India
}

\author{
Divija Sawant \\ Department of Computer \\ Engineering, Sinhgad Institute of \\ Technology and Science, Pune- \\ 411041, India
}

\author{
Manikant Dubey \\ Department of Computer \\ Engineering, Sinhgad Institute of \\ Technology and Science, Pune- \\ 411041, India
}

\author{
Mrunal Pandole \\ Department of Computer Engineering, Sinhgad \\ Institute of Technology and Science, Pune-411041, \\ India
}

\author{
Pooja Vengurlekar \\ Professor \\ Department of Computer Engineering, Sinhgad \\ Institute of Technology and Science, Pune-411041, \\ India
}

\begin{abstract}
Home automation is a modern technology that allows you to modify your home to perform a different set of tasks automatically. Home automation is growing drastically due to increasing demands in a wide range of sectors. The proposed system deals with the technology called Sixth sense. Sixth Sense, also known as wear your world (WUW) is a wearable gestural interface, that enhances the physical world around us with digital information and allows us to use natural hand gestures to interact with that information. The aim behind this approach is to develop and engineer a system which is trained to recognize and percept gestures of a human arm using a smart glove. This smart glove can be embedded with flex sensors which sense the finger bends. With the help of these sensor inputs, the electronic appliances such as light bulbs, fans, etc can be controlled. The inputs would be taken from the sensors and processed using Arduino board. Other sensors like the LDR sensor and the DHT sensor would be used to check the intensity and temperature in the room respectively. This sensor data would be displayed on an Android application which would also consist of alternative UI components to control the electronic devices (lights, fans, etc.). If the temperature or humidity changes drastically then an alarm would be triggered on our Android application. The methodology used in this approach is based on the fields of Sixth sense technology, Embedded Systems and Android.
\end{abstract}

\section{General Terms}

Android Application, Sensors, Embedded Systems.

\section{Keywords}

Sixth Sense, Home Automation, Arduino, Gestural Interface, Flex sensor, LDR sensor, DHT sensor.

\section{INTRODUCTION}

Humans, over millions of years have been using their five natural senses, namely the eyes, ears, nose, tongue and touch to interact with the environment around them. These natural senses allow us to perceive any form of information from our surrounding environments and help us learn about everything happening around us in many perspectives, ultimately helping us in making wise decisions and taking appropriate actions that would be beneficial to the mankind.

Today we live in the 21 st century, an era that is marked by rapid technological advancements. Such advancements have lit the world, made life easier and better, opened easier ways of communication, helped to make learning interesting, has helped business grow and boosted scientific research.

In this modern technology based environment that is changing the lifestyles of mankind at such a lightning speed, our natural senses are proving to be inadequate to perceive the most useful information that would lead us in making the best decisions in various real and hypothetical situations. Today, with the ever growing technological revolution, it has been possible to interface the digital information with the physical world. The miniaturization of computing devices allows us to carry them anywhere keeping us connected with the digital world. However, there is no link between our digital devices and our interactions with the physical world. This calls for a need of a technology that would help in bridging this gap by giving out the digital information to the tangible world and giving us the opportunity to interact with this information using out natural hand gestures. The desire to serve this need laid the foundations of a new paradigm called the Sixth Sense Technology.

Sixth Sense Technology, as the name suggests, is the one that allows people to interact physically with a digital world that has been augmented on their physical world, thus giving them the sense of owning a sixth sense. It is a wearable gestural interface that imposes visible digital data onto the physical world for users to interact with the digital world. Sixth sense, thus, is also known as WUW(Wear your World), wherein using computer vision, augmented reality, radio frequency identification and gesture recognition, we are brought a step closer to reality. The initial prototype was developed by Steve Mann, MIT Media Lab student, which was a neck worn projector with a camera for implementing the sixth sense technology. Later on, Pattie Maes and Pranav Mistry, a Ph. D student at Fluid Interfaces Group at the MIT Media Lab, further worked on this concept and developed an augmented 
system which they call Sixth Sense, presented in TEDx conference in 2009.

The sixth sense prototype proposed by Pranav Mistry demonstrates the usefulness, flexibility and viability of this system. The components needed to develop the prototype include a camera, projector, colored markers, a mirror and a mobile phone. The camera identifies the gestures one makes using hands. It also recognizes images, individuals and pictures. The collected information is given to the Smart phone to process it. The output image is projected on to the mirror with the help of a downward facing projector. Mirror reflects the image on the desired surface. Thus, digital information is freed from its confines and placed in the physical world. This technology, based on hand gesture recognition, image capturing, processing, and manipulation etc. recognizes the objects around you, displaying the information automatically and letting you access it in any way you want and in the simplest way possible.

Thus, it can be said that Sixth Sense technology is the science of tomorrow with the aim of connecting the digital world with the physical world seamlessly and allowing humans to interact with their physical world like never before. With its sheer potential, it is likely to become the next mass media revolutionizing the world is all aspects.

The further sections of the paper are structured as - Existing Methodologies, Proposed System, Acknowledgement, Conclusion and References.

\section{EXISTING METHODOLOGIES}

Home automation is a modern system in which all the electrical appliances are inter-networked together in order to provide us with a seamless control over all aspects of the smart home space. It includes control and remote monitoring of heating, ventilation, air-conditioning (HVAC) and lighting aspects as well as the control over electrical appliances such as ovens, dryers/washers, refrigerators /freezers etc. The home devices act as smart devices and are networked over the internet, forming the important components of Internet of Things (IoT) . An IoT based home automation system allows you to have a feel of complete control of your home, from anywhere. One can remotely dictate how he/she want the devices to react based on his/her personal choice or preference thus providing a user-governed smart home that makes human life much more comfortable and easier.

While it is known that an IoT based home automation paves way for an extremely convenient and interesting lifestyle, there are certain limitations that cannot be overlooked. One of the biggest drawbacks is the equipment and installation costs. In IoT based automation, sensors have to be deployed along with other hardware on a large scale. The automation cost totally depends on the number of equipments you install in your house. The more advanced the system, the more expensive it becomes as it would offer more features. Another drawback is the reliability of the sensors. The accuracy measure of the sensor output cannot be pre-determined. Hence reliability of the sensor results cannot be guaranteed. A more reliable sensor device, consequently incurs higher cost. Thus, although the home automation system developed using Internet of Things makes a person's life more convenient, it becomes a very costly affair in the long run.

Sixth sense technology, also known as Extra Sensory Perception (ESP) in scientific terms, allows us to perceive the information beyond what can be acquired through our natural senses, enabling us to communicate directly with the physical world using symbols, hand gestures or images. The basic motive behind using sixth sense to develop a home automation system is to engineer a wearable gestural interface that would promote a cost effective automation system. The research carried out on the existing sixth sense based home automation showcases a client server network system. In this system, the user shows images drawn on paper to the web camera of the laptop. It creates a machine vision and image processing application using Lab View VI. Machine vision permits the computer to capture images. These images are used to turn on or turn off the electronic devices. This can be done by establishing client-server network for data transmission. The Raspberry PI acts as a server which receives information based as per the images from the client through TCP/IP connection. It is connected to the hardware devices which receives information sent by it via relay circuits and appliances are controlled accordingly.

Advantages of using such a system:

1. Allows parallel programming

2. Code optimization using python

3. Supports real time access.

Limitations:

1. The techniques which are required to implement a $\mathrm{G}$ programming language are of a very high quality.

2. The memory management and the syntax of Lab View should be properly known by the programmer so as to implement algorithms which are complex and complicated.

3. Images need to be drawn and must be understood by the Lab View application.

In order to overcome the above limitations a compact and cost effect sixth sense based automation system using a smart glove is proposed that works on the principle of gesture acquisition and corresponding control signal generation.

\section{PROPOSED SYSTEM}

The proposed system deals with a smart glove that is used for home automation. The input to the system is the hand gesture, given by the smart glove. The glove is deployed with flex sensors. The word flex means" bend". It is a resistive type of sensor. This sensor is used as a transducer which converts the physical energy into electrical energy.

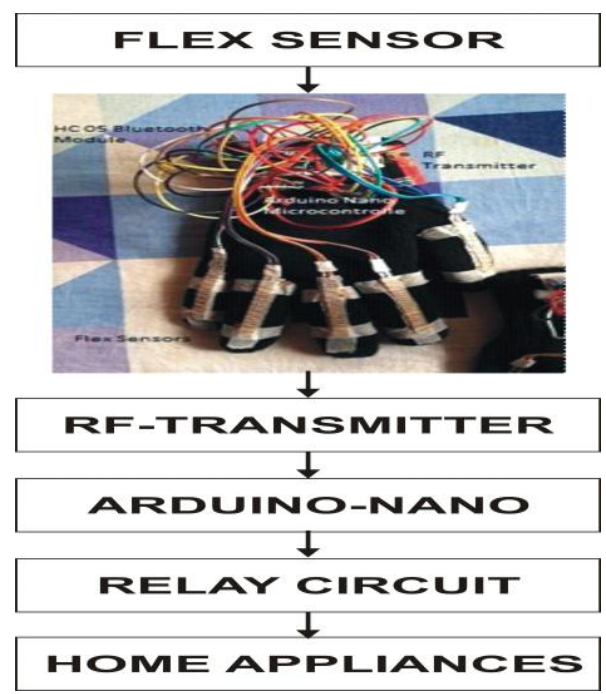

Figure1: Proposed System 
Flex sensors are placed over the fingers. As the fingers bend the resistance of the flex sensor changes depending upon the amount of bend and it converts it into analog voltage. The input from the sensors is given to RF-433MHz transmitter and receiver. This RF module is used to transmit the data. The operating voltage for transmitter is $3 \mathrm{~V}-12 \mathrm{~V}$ and that of the receiver is $5 \mathrm{~V}$. With the help of RF module the data is then sent to the microcontroller i.e arduino nano/uno. The microcontroller is based on Atmega 328k having 20 input/output digital pins and 7 PWM pins. Arduino IDE is used as a cross platform for development of applications. The microcontroller processes the input voltage and sends control signals to the Relay driver IC Circuit. Relay driver enables a low power circuit to control signals or to shift high current $\mathrm{ON}$ and OFF. Relay circuits are useful when there is a need to control large amount of current or voltage. From the relay driver, control signals are then sent to various home appliances like fans, ACs, bulbs etc. And hence the appliances are controlled using sixth sense technology.

\section{CONCLUSION}

The proposed system aims to design a cost effective system that would enable people to automate their homes by means of a single wearable interface -the customized smart glove. This system would be beneficial for common man as well as the physically disabled as one can operate the appliances sitting on one place. Based on the research so far, it can be concluded that this system will be a new, innovative approach towards home automation as it reduces the cost considerably and is user friendly as well.

In future, the proposed system can be made more efficient by increasing the accuracy of the system by resolving ambiguity issues in case of similar gestures. Advanced features like 3D gesture tracking can be incorporated. As this system is also beneficial for the handicapped, another future advancement would be to make the sixth sense work as a fifth sense for the disabled.

\section{ACKNOWLEDGEMENT}

This research was carried out under the keen guidance of Prof. Pooja N. Vengurlekar.

\section{REFERENCES}

[1] S.Pradeep Kumar, Asst. Prof, Rajalakshmi of technology , Chennai , O. Pandithurai Phd (scholar ) Anna university of Technology Comibatore, India "Sixth Sense Technology", IEEE , February 2015

[2] "Sixth Sense Technologies: A Review Paper", Volume 5, Issue 2, February 2015 ISS 2277 128X International Journal of Advanced Research in Computer Science and Software Engineering Research Paper.Available online at: www.ijarcsse.com.

[3] Dr. Ashwani Kush Associate Professor ,Computer Department, University College, Kurukshetra University Kurukshetra, Haryana, India, "Sixth Sense Technology, A New Paradigm ", IEEE 2015.

[4] Allan Shivji, Student: BE Computer Engineering, St. John College of Engineering and Technology, Mumbai, India, "Sixth Sense Technology: Applications and Comparisons" IEEE 2016.

[5] Jash Mehta, Nirav Nayan and Lakshmi Kurup, "A Review Paper on Sixth Sense Technology" International Journal of Current Engineering and Technology E-ISSN 2277 - 4106, P-ISSN 2347 5161 .

[6] Zeenat A Kassim and Nader Mohamed College of Engineering, College of Information Technology UAE University, " Sixth Sense Technology: Comparisons and Future Prediction ", Al Ain, UAE 201370466.

[7] Ajit Manware, Rajnish Raj, Amit Kumar, Tejaswini Pawar, "Smart Gloves as a Communication tool for the Speech Impaired and Hearing Impaired", June 2017, Volume 4, Issue 06 JETIR (ISSN-2349-5162) JETIR1706018 Journal of Emerging Technologies and Innovative Research (JETIR) www.jetir.org 78 Dept. Of Computer Engineering, Sinhgad Institute Of Technology, Lonavala, India. College of Engineering and Technology Mumbai

Comparison". 